\title{
PENERIMAAN DIRI PADA ISTRI YANG MEMILIKI SUAMI HOMOSEKSUAL
}

\author{
Irma Rosalinda Lubis* \\ Ananda Rasullia** \\ *Jurusan Psikologi, Universitas Negeri Jakarta \\ **Jurusan Psikologi, Universitas Negeri Jakarta
}

DOI: https://doi.org/10.21009/JPPP.032.06

\author{
Alamat Korespondensi: \\ irmarosas@unj.ac.id
}

\begin{abstract}
This research was conducted to find the stages of self-acceptance in wife with homosexual husband. The stages of self-acceptance taken from Christopher Germer's stages of self-acceptance and consists of five stages; aversion, curiosity, tolerance, allowing, and friendship. This research also wanted to find out the reason underlying why a wife still keeping her marriage alive with homosexual husband.This research was conducted using qualitative methods because the phenomenon to be studied belong to a unique phenomenon. This research uses purposive sampling technique to selected its subject. The approach used in this research is case study. Study results showed that both of the subjects are already achieved three out of five stages of self-acceptance. The reason why they still keeping up their marriage alive are because of affection towards the husband, religion factor, and family factor
\end{abstract}

Keywords

self-acceptance, homosexual

\section{Pendahuluan}

Suatu pernikahan pada umumnya terjadi antara dua orang dengan orientasi seksual yang sama, yaitu heteroseksual. Ketika terjadi pernikahan antara dua orang dengan orientasi seksual yang berbeda, hal tersebut dapat menyebabkan ketidakseimbangan dalam kehidupan pernikahan dan bahtera rumah tangga. Menurut para pasangan heteroseksual, mengetahui bahwa pasangan mereka bukan seorang heteroseksual merupakan pengalaman yang traumatis (Schwartz, 2012). Penelitian Buxton dan Schwartz (2004) menemukan bahwa pasangan heteroseksual yang menikah dengan suami homoseksual mengaku bahwa mereka tidak menyadari bahwa pasangan yang mereka nikahi merupakan seorang homoseksual.
Buxton (2004) menyebutkan bahwa ketika pasangan heteroseksual mengetahui pasangannya adalah seorang gay, mereka merasa seolah-olah dunia tempat kaki mereka berdiri dibelah secara paksa. Meskipun pada awalnya mereka merasa curiga dengan orientasi seksual pasangannya, mengetahui kenyataan bahwa suaminya benarbenar seorang gay adalah hal yang menyakitkan.

Pada bulan-bulan pertama, rasa shock dan ketidakpercayaan masih membayangi pasangan heteroseksual. Penelitian Hays dan Samuels menemukan bahwa respon umum yang ditunjukkan oleh mayoritas istri yang memiliki suami homoseksual sesaat setelah mengetahui bahwa suaminya adalah seorang homoseksual adalah rasa marah, cemburu, merasa tersakiti, sedih, dan rasa jijik. 17 dari 18 istri mengaku merasakan kemarahan sesaat setelah mereka tahu bahwa mereka menikah dengan suami homoseksual, 16 
istri merasa tertekan, kesepian, serta merasa bahwa kehidupan pernikahannya sudah tidak memiliki masa depan lagi, 12 istri mengalami reaksi fisik, seperti penurunan berat badan, sakit kepala, ataupun kehilangan nafsu makan. Satu orang istri langsung jatuh sakit dan harus dirawat di rumah sakit. 6 orang mengaku merasa gelisah dan menyalahkan diri mereka sendiri karena tidak memperhatikan perilaku aneh sang suami, atau menyalahkan diri sendiri karena menganggap diri mereka belum menjadi seorang istri yang baik.

Berdasarkan hasil wawancara pribadi, seorang istri yang menemukan kenyataan secara tiba-tiba bahwa pasangannya adalah seseorang yang memiliki ketertarikan dengan sesama jenis, mengalami rasa shock dan kecewa. Banyak dari mereka yang menyalahkan diri sendiri akan tragedi yang menimpa kehidupan rumah tangganya. Kebanyakan dari mereka serta merta langsung menutup diri dari lingkungan karena malu akan keadaan yang tengah dialami.

Memiliki pasangan hidup yang berbeda orientasi seksual tentu terasa berat. Hal ini dapat menyebabkan perasaan depresi serta kekecewaan yang mendalam bagi para istri. Tidak sedikit dari mereka yang memutuskan untuk memutus ikatan pernikahan karena memiliki pasangan hidup seorang homoseksual, tetapi tidak sedikit pula yang memilih untuk tetap mempertahankan bahtera rumah tangga. Menurut hasil penelitian Hays dan Samuels (dalam Hernandez dkk, 2011), mengalami kesedihan, isolasi sosial, dan merasa dibohongi adalah respon-respon yang umum diperlihatkan wanita setelah mereka mengetahui bahwa pria yang mereka nikahi adalah seorang homoseksual. $48 \%$ dari partisipan mengambil tindakan perceraian, berpisah, dan berencana untuk meninggalkan suami mereka. Wanita tidak merasa bebas untuk mencari dukungan dari teman dan keluarga karena ketakutan akan stigma, sedangkan 52\% lainnya memutuskan untuk bertahan dengan pernikahannya, meskipun merasa tidak yakin bahwa pernikahan akan berlangsung lama.

Menjalani kehidupan dan dihadapkan pada kejadian-kejadian yang menyakitkan, seringkali membuat seseorang merasa bahwa ialah penyebab dari segala terjadinya kejadian menyakitkan dalam hidupnya. Hal tersebut dapat menyebabkan dirinya tidak mampu untuk menerima diri sendiri tanpa syarat. Menyalahkan diri sendiri atas terjadinya kejadian-kejadian yang menyakitkan tersebut dapat memicu ketidakmampuan seseorang dalam menerima diri sendiri tanpa syarat. Sementara, penerimaan diri adalah kesehatan mental yang krusial. Ketidakmampuan untuk menerima diri sendiri tanpa syarat dapat memicu kesulitan-kesulitan emosional, termasuk kemarahan yang tidak terkontrol dan depresi (Carson \& Langer, 2006). Maslow (dalam Levianti, 2013) mendefinisikan penerimaan diri sebagai sikap positif terhadap dirinya sendiri, dapat menerima keadaan dirinya secara tenang dengan segala kelebihan dan kekurangannya. Mereka bebas dari rasa bersalah, rasa malu, dan rendah diri akibat dari keterbatasan diri serta kebebasan dari kecemasan atas adanya penilaian dari orang lain.

Kejadian traumatis tentu tidak dapat dihindari oleh siapapun, tetapi kemampuan individu dalam memahami bahwa suatu kegagalan adalah bagian dari perjalanan kehidupan dapat membantu individu dalam menumbuhkan rasa penerimaan diri yang baik. Selain itu, kemampuan dalam menghadapi rasa sakit dan kecewa yang terjadi akibat kenyataan bahwa seseorang memiliki suami homoseksual juga mampu menumbuhkan rasa penerimaan diri yang baik dalam diri individu tersebut. Penerimaan diri merupakan hal yang sangat penting untuk dimiliki oleh seseorang. Jika seseorang tidak mampu untuk menerima dirinya, maka ia akan sulit untuk merasa bahagia dengan apa yang telah ia miliki, serta sulit untuk beradaptasi dengan lingkungan dan mencintai dirinya sendiri. Seorang istri heteroseksual yang memiliki suami nonheteroseksual, seperti yang telah dibahas, memiliki kemungkinan besar mengalami ketidakbahagiaan karena dipicu oleh perasaan kesedihan, isolasi sosial dan kekecewaan. Oleh karena itu, penelitian ini bertujuan untuk mengetahui gambaran tahap penerimaan diri pada istri yang memiliki suami homoseksual.

\section{Metode Penelitian}

Tipe penelitian yang digunakan ini adalah penelitian kualitatif studi kasus. Kasus merupakan fenomena khusus yang hadir dalam suatu konteks yang terbatasi. Kasus itu dapat berupa individu, peran, kelompok kecil, organisasi, komunitas, atau bahkan suatu bangsa. 
Studi kasus merupakan uraian dan penjelasan komprehensif mengenai berbagai aspek seseorang individu, suatu kelompok, suatu organisasi (komunitas), suatu program, atau suatu situasi sosial. Unit analisis yang dimaksud adalah individu atau seseorang, kelompok, atau organisasi. Tujuan penelitian studi kasis adalah deskripsi tentang konteks dan terjadinya suatu kasus. Selain itu, fokus utama penelitian studi kasus juga dapat diarahkan pada pembahasan tentang tema, isu, dan implikasi yang ada pada suatu kasus.

Pemilihan subjek yang sesuai dengan penelitian ini adalah secara purposive, yaitu dipilihnya dengan pertimbangan dan tujuan tertentu. Purposive sampling digunakan dalam situasi dimana peneliti memilih kasus untuk tujuan tertentu. Dalam purposive sampling, hasil penelitian tidak akan digeneralisasikan ke populasi karena pengambilan subjek tidak diambil secara random. Karakteristik subjek yang digunakan dalam penelitian ini adalah (1) subjek adalah pasangan suami istri secara sah yang terikat dalam perkawinan. Menurut Undang-undang Republik Indonesia nomor 1 tahun 1974, perkawinan adalah ikatan lahir batin antara seorang pria dan seorang wanita sebagai suami istri dengan tujuan membentuk keluarga atau rumah tangga yang bahagia dan kekal berdasarkan Ketuhanan Yang Maha Esa, (2) subjek memiliki suami berorientasi homoseksual, sementara subjek sebagai istri memiliki orientasi heteroseksual, (3) pernikahan subjek dengan suami berusia 1 (satu) tahun atau lebih dari 1 (satu) tahun, (4) subjek dengan pasangan belum memiliki anak kandung. Penelitian ini dilakukan pada bulan April sampai dengan awal bulan Juli tahun 2013. Pengambilan data dimulai pada tanggal 19 April 2013. Penelitian dilakukan melalui komunikasi online via aplikasi chatting Whatsapp dan Facebook Messenger dan wawancara tatap muka yang bertempat di salah satu hotel dan restoran di kota Madiun, serta hotel di kota Yogyakarta yang dekat dengan domisili subjek penelitian. Komunikasi online via aplikasi chatting dilakukan karena lokasi subjek yang berdomisili di luar Pulau Jawa, sulit dijangkau, dan permintaan subjek untuk wawancara melalui aplikasi chatting karena subjek tidak menginginkan identitasnya diketahui oleh siapapun.

\section{Hasil Penelitian dan Diskusi}

Tahap ini merupakan tahap awal yang terjadi ketika individu dihadapkan pada kejadian yang tidak menyenangkan. Germer (2009) menjelaskan bahwa dalam tahap ini terjadi reaksi naluriah dan reaksi pertama individu apabila dihadapkan dengan perasaan yang tidak menyenangkan yaitu melakukan penolakan. Aversi atau penolakan dapat terjadi dalam bentuk ruminasi atau perenungan, individu mencoba untuk menghilangkan perasaan tidak menyenangkan yang dialami. Menurut acuan teoritik, SI dan SC telah melewati tahap penolakan karena pada awal mereka mengetahui bahwa suami mereka adalah seorang homoseksual, sempat terjadi beberapa reaksi penolakan dan penghindaran dari masalah. Berbagai pertanyaan-pertanyaan muncul dalam diri mereka, mempertanyakan perihal kemengapaan mereka diberikan suami yang istimewa.

SI dan SC keduanya mengalami rasa syok, sedih, dan marah saat itu. Perbedaannya adalah, SI mengetahui bahwa suaminya adalah seorang homoseksual pada usia 6 bulan pernikahan, sedangkan SC mengetahuinya sebulan sebelum pernikahan, tetapi keduanya sempat memiliki pikiran yang sama, yaitu keinginan untuk berpisah dengan suami ataupun membatalkan pernikahan.

Pada tahap keingintahuan, Germer (2009) menjelaskan tahap ini merupakan keadaan dimana individu akan mengalami rasa penasaran dan keingintahuan mengenai permasalahan yang mereka hadapi, sehingga mereka ingin mempelajari mengenai permasalahannya lebih lanjut. Setelah melewati tahap penolakan, SI dan SC mulai mencari tahu mengenai permasalahan yang sedang mereka hadapi. Keduanya kemudian bergabung dengan komunitas Menanti Mentari yang beranggotakan para istri dengan suami homoseksual dengan tujuan dapat berkeluh kesah dan berbagi mengenai hal yang sama, hanya saja SC tidak terlalu suka untuk terlalu mendalam bercerita dengan anggota lain karena takut dirinya akan merasa tambah sakit hati.

Baik SI maupun SC, keduanya tidak ada yang bercerita mengenai masalah yang sedang mereka alami kepada orang terdekat seperti keluarga maupun sahabat. Keduanya lebih memilih untuk diam dan menyimpan masalahnya sendiri. Bahkan dalam komunitas pun mereka berdua aktif dalam 
identitas samara, jadi tidak ada yang tahu identitas asli mereka.

Toleransi berarti individu mencoba menahan perasaan tidak menyenangkan yang tengah dirasakan, dengan harapan perasaan tersebut akan hilang dengan sendirinya (Germer, 2009). Setelah mengalami masa keterpurukan, SI dan SC kemudian mencoba bangkit dan belajar menerima keadaan sekaligus keistimewaan suami. Keduanya berusaha untuk menemani dan mendukung suami dalam berhijrah meninggalkan masa lalunya. SI dan SC berusaha untuk menguatkan suaminya agar tidak kembali ke masa-masa sebelum menikah. SC, dengan HIV yang sedang hinggap dalam tubuh suaminya, selalu berusaha untuk mencoba menghibur suaminya ketika sang suami merasa sedih setiap pulang kontrol.

Keduanya tetap berusaha untuk menemani dan membantu suami agar tetap berjalan lurus di jalan Tuhan Yang Maha Esa meskipun tidak jarang merasa curiga terhadap suaminya. SI bahkan sering merasa curiga dengan suami jika suami telat membalas pesan dan mengangkat telepon.

Sementara jika dianalisis menggunakan teori Kubler-Ross, maka kedua subjek sama-sama masih dalam tahap depresi. Tahap pertama merupakan tahap penolakan. Penolakan merupakan reaksi yang wajar bagi seorang individu ketika dihadapkan pada situasi yang tidak menyenangkan. Dalam kasus penelitian ini, kedua subjek mengalami tahap penolakan ketika baru saja mengetahui bahwa suaminya adalah laki-laki homoseksual. kedua subjek mengalami rasa syok, sedih dan marah ketika mengetahui bahwa suami mereka adalah lelaki homoseksual. Subjek SI sempat berpikir dan menawarkan suaminya untuk berpisah, sedangkan subjek SC sempat memiliki keinginan untuk membatalkan pernikahan. Subjek SI sempat berpikir dan menawarkan suaminya untuk berpisah, sedangkan subjek SC sempat memiliki keinginan untuk membatalkan pernikahan. SC juga sempat tidak memercayai bahwa suaminya homoseksual ketika mendapatkan kiriman berupa foto dan video dari mantan kekasih calon suaminya kala itu dan langsung menanyakan hal tersebut kepada calon suami untuk mendapat klarifikasi. SC juga sempat tidak percaya saat calon suaminya mengatakan bahwa ia mengidap HIV.
Setelah menolak, maka individu kemudian mengekspresikan kemarahannya. Individu yang merasa kecewa dapat merasa marah kepada dirinya sendiri maupun kepada orang lain. Kedua subjek dalam penelitian ini mengalami rasa marah terhadap dirinya sendiri maupun suaminya. Subjek SC merasa marah dan kecewa dengan dirinya sendiri karena ia harus mengetahui mengenai orientasi seksual dan penyakit suaminya satu bulan sebelum pernikahan, padahal menurutnya, ia bisa saja mengetahui hal tersebut jauh sebelum merencanakan pernikahan. Sementara, subjek SI juga merasakan hal yang sama seperti subjek SC, yaitu rasa marah dan kecewa, serta rasa sedih. Keduanya melampiaskan rasa kemarahan kepada Tuhan Yang Maha Esa dengan mempertanyakan dosa dan perilaku buruk apa yang telah mereka perbuat sehingga mereka diberikan suami seorang lelaki homoseksual.

Dalam tahap tawar menawar, subjek pertama, yaitu SI mengatakan bahwa jika saja dirinya dan suami dapat tinggal bersama, kemungkinan ia akan dapat lebih menata hatinya dan merasa lebih tenang, karena saat ini masalah menjalani hubungan jarak jauhlah yang menyebabkan rasa curiga sering muncul. Subjek kedua, yaitu SC, meminta kepada Tuhan Yang Maha Esa agar diberikan kekuatan dalam mengambil keputusan dalam menerima keadaan suaminya agar ia dapat menerima seluruh kemungkinan terburuk yang mungkin akan terjadi.

Dalam tahap depresi Kubler-Ross, terdapat dua jenis depresi, yaitu depresi reaktif, dimana perasaan kesedihan yang muncul karena sesuatu yang telah terjadi, dan depresi preparatori, yaitu perasaan kesedihan yang muncul karena ketakutan akan kehilangan yang akan terjadi di masa depan. Dalam penelitian ini, subjek pertama yaitu SI mengaku sempat mengalami periode depresi selama satu tahun setelah ia mengetahui bahwa suaminya adalah lelaki homoseksual. SI sempat kehilangan nafsu makan, menangis setiap malam hingga pagi, hingga mengalami penurunan berat badan yang cukup drastis. Tahap depresi yang dialami oleh SI merupakan depresi reaktif dalam tahap depresi Kubler-Ross. Sementara, meskipun subjek SC mengakui bahwa ia merasa takut jika suaminya akan meninggalkan dirinya, tetapi SC tidak mengalami apa yang SI alami, seperti kehilangan nafsu makan dan menangis 
bermalam-malam. SC memilih untuk tetap menjaga kesehatan tubuhnya dan mencoba untuk tetap berpikiran positif.

\section{Kesimpulan}

Subjek SI belum mencapai tahap keempat dan kelima karena meskipun subjek sudah mampu untuk mengesampingkan perasaan tidak menyenangkan mengenai masalahnya dan berusaha untuk menjalankan perannya sebagai istri dengan baik, serta mengambil hikmah dari masalah yang ia dapatkan. tetapi, SI belum secara utuh berdamai dengan masalah tersebut karena ia masih menyimpan rasa curiga yang besar kepada suami. SI juga masih merasa cemburu dan sering marah ketika suaminya tidak lekas mengangkat telepon atau membalas pesan. Meskipun begitu, SI yang dulu selalu kesal setiap melihat suaminya, sekarang sudah tidak merasa kesal lagi dan SI selalu mendoakan agar suaminya dapat kembali ke fitrah.

Serupa dengan subjek SI, subjek SC pun belum mencapai tahap keempat dan kelima karena meskipun subjek sudah mampu mengesampingkan perasaan tidak menyenangkan mengenai masalahnya dan berusaha untuk memberikan motivasi dan dukungan yang besar kepada suaminya, serta mengambil hikmah dari dari masalah yang ia hadapi, SC juga masih menyimpan rasa curiga terhadap suaminya terutama jika suaminya terlalu lama berada di dekat handphone. Ia masih merasa takut bahwa suaminya akan berpaling kembali ke dunia LGBT dan meninggalkan pernikahannya, namun SC sebisa mungkin menekan perasaan curiga tersebut dengan menanyakan aktivitas apa yang suaminya lakukan di handphone.

Jika dijelaskan dengan teori dari Kubler-Ross yang terdiri dari lima tahap, yaitu tahap penolakan, tahap kemarahan, tahap tawar menawar, tahap depresi, dan tahap penerimaan, maka dapat disimpulkan bahwa subjek SI dan SC masih dalam tahap depresi karena SI masih menyimpan rasa kesedihan dan kekecewaan akibat perbuatan suaminya di masa lalu, dan SC merasa takut akan ditinggalkan oleh suaminya.

\section{Daftar Pustaka}

Buxton, A. P. \& Schwartz, L. B. (2004). Straight Spouses Speak Out: Implications for Gay and Lesbian Marriage. Journal of Health Promotion. 2, Special Issue: LGBT; 24-31.

Carson, S. H., \& Langer, E. J. (2006). Mindfulness and Self-Acceptance. Journal of Rational-Emotive \& Cognitive Behavior Therapy. 24(1)

Feldman, R. S. (2009). Development Across the Life-Span. Ed. 5. New Jersey: Pearson Education, Inc.

Germer, C. K. (2009). The Mindful Path to SelfCompassion: Freeing Yourself from Destructive Thoughts and Emotions. New York: The Guilford Press.

Hernandez, B. C., Schwenke, N. J., \& Wilson, C. M. (2011). Spouses in Mixed-Orientation Marriage: A 20-Year Review of Empirical Studies. Journal of Marital and Family Therapy, 37(3).

Schwartz, L. (2012). Mixed-Orientation Marriages: Coming Out, Staying Together. Journal of GLBT Family Studies. 